\title{
Nut consumption and prostate cancer risk and mortality
}

\author{
Weike Wang ${ }^{1,6}$, Meng Yang ${ }^{2,6}$, Stacey A Kenfield ${ }^{3}$, Frank B Hu ${ }^{1,2,4}$, Meir J Stampfer ${ }^{1,2,4}$, Walter C Willett ${ }^{1,2,4}$, \\ Charles S Fuchs ${ }^{4,5}$, Edward L Giovannucci ${ }^{1,2,4,7}$ and Ying Bao*,4,7 \\ ${ }^{1}$ Department of Epidemiology, Harvard T.H. Chan School of Public Health, 677 Huntington Avenue, Boston, MA 02115, USA; \\ ${ }^{2}$ Department of Nutrition, Harvard T.H. Chan School of Public Health, 677 Huntington Avenue, Boston, MA 02115, USA; ${ }^{3}$ Department of \\ Urology, University of California, San Francisco, 550 16th Street, San Francisco, CA 94143, USA; ${ }^{4}$ Channing Division of Network \\ Medicine, Department of Medicine, Brigham and Women's Hospital, and Harvard Medical School, 181 Longwood Avenue, Boston, MA \\ 02115, USA and ${ }^{5}$ Department of Medical Oncology, Dana-Farber Cancer Institute, 450 Brookline Avenue, Boston, MA 02215, USA
}

Background: Little is known of the association between nut consumption, and prostate cancer (PCa) incidence and survivorship.

Methods: We conducted an incidence analysis and a case-only survival analysis in the Health Professionals Follow-up Study on the associations of nut consumption (updated every 4 years) with PCa diagnosis, and PCa-specific and overall mortality.

Results: In 26 years, 6810 incident PCa cases were identified from 47299 men. There was no association between nut consumption and being diagnosed with PCa or PCa-specific mortality. However, patients who consumed nuts five or more times per week after diagnosis had a significant $34 \%$ lower rate of overall mortality than those who consumed nuts less than once per month $(H R=0.66$, 95\% Cl: 0.52-0.83, P-trend =0.0005).

Conclusions: There were no statistically significant associations between nut consumption, and PCa incidence or PCa-specific mortality. Frequent nut consumption after diagnosis was associated with significantly reduced overall mortality.

Nuts are rich in bioactive macronutrients, micronutrients, tocopherols and phytochemicals (Ros et al, 2010). Current epidemiological evidence has consistently linked increased nut consumption to reduced risk of several chronic conditions including cardiovascular diseases, type 2 diabetes, and inflammation (Ros, 2010; Afshin et al, 2014). In contrast, evidence on nut consumption and cancer risk has been insufficient and equivocal (González and Salas-Salvadó, 2007). Prostate cancer $(\mathrm{PCa})$ is the leading cancer among US men (Siegel et al, 2015), with $\sim 220800$ new PCa cases diagnosed in 2015 (American Cancer Society, 2015). Studies regarding nut intake and PCa incidence are limited and have reported inconsistent results (Mills et al, 1989; Hebert et al, 1998; Jain et al, 1999; Raimondi et al, 2010). Furthermore, few studies have investigated nut intake in relation to survival among PCa patients and in one that has the associations were suggestive, but not statistically significant (Richman et al, 2013). Thus, in the current study, we prospectively examined nut consumption in relation to $\mathrm{PCa}$ incidence and PCa-specific mortality in a large cohort of male health professionals.

\section{MATERIALS AND METHODS}

For details on methods see Supplementary Material.

Study population. The Health Professionals Follow-up Study (HPFS) is a prospective cohort study of US male health professionals established in 1986 (Kenfield et al, 2014). After exclusion criteria, the final incidence analysis included 47299 men and the final case-only survival analysis included $4346 \mathrm{PCa}$ patients without metastasis at diagnosis, followed through January 2012.

Assessment of dietary and non-dietary factors. Participants completed a validated semi-quantitative food frequency questionnaire (FFQ) at baseline and every 4 years thereafter. They were asked how

*Correspondence: Dr Y Bao; E-mail: ying.bao@channing.harvard.edu

${ }^{6}$ These authors contributed equally to this work and share co-first authorship.

${ }^{7}$ These authors contributed equally to this work and share co-senior authorship. 
often they consumed a serving (serving size, $28 \mathrm{~g}(1 \mathrm{oz})$ ) of peanuts and other nuts during the preceding year. Total nut consumption was defined as the sum of peanut and other nut consumption. A validation study of the FFQ indicated that nuts were reported reasonably accurately (Salvini et al, 1989). We also obtained information on other lifestyle factors and medical history.

Ascertainment of PCa. PCa diagnosis was confirmed with medical records and pathology reports. Family reports and National Death Index searches were used to identify deaths. We examined hazard ratios (HR) with respect to the following categories of PCa: total (excluding T1a cancers), advanced, lethal, fatal, low-grade (Gleason score 2-6) and high-grade (Gleason score $\geqslant 7$ ). Advanced PCa was defined as stage T3b, T4, N1, or M1 at diagnosis, or lymph node metastases, distant metastases, or PCa death during follow-up. Lethal cancer, the primary focus of our study, was defined as cases that metastasised to distant organs at diagnosis or over follow-up, or that caused PCa death. Fatal cancers were defined as those that caused PCa death. We also investigated post-diagnostic nut intake in relation to development of lethal $\mathrm{PCa}$, fatal $\mathrm{PCa}$, and all-cause mortality among men diagnosed with localised or regional PCa (clinical stage T1-T3a).

Statistical analysis. Cox proportional hazards models were used to estimate HR and 95\% confidence intervals (CIs).

PCa incidence analysis. Men were followed from return of baseline questionnaire until diagnosis, death, or 31 January 2012. Nut consumption was presented as a cumulative average from 1986 to end of follow-up. In secondary analyses, we assessed interactions by ethnicity, age, and BMI, added a 2-year lag period between nutintake assessment and each follow-up period, and further examined baseline nut intake in relation to being diagnosed with PCa.

Case-only survival analysis. For lethal $\mathrm{PCa}$, men were followed from PCa diagnosis to metastases. For fatal $\mathrm{PCa}$, men were followed from PCa diagnosis to death from PCa. For all-cause mortality, men were followed from PCa diagnosis until death by any cause or 31 January 2012. Nut consumption was presented as a cumulative

Table 1. Hazard ratios and $95 \%$ confidence intervals of prostate cancer, according to the total nut consumption

\begin{tabular}{|c|c|c|c|c|c|c|}
\hline & \multicolumn{5}{|c|}{ Frequency of total nut consumption ( $28 \mathrm{~g}$ serving) } & \multirow[b]{2}{*}{$P$ for trend } \\
\hline & $\begin{array}{l}\text { Less than once } \\
\text { per month }\end{array}$ & $\begin{array}{l}\text { Less than once } \\
\text { per week }\end{array}$ & Once per week & $\begin{array}{l}\text { 2-4 Times per } \\
\text { week }\end{array}$ & $\begin{array}{c}\geqslant 5 \text { Times per } \\
\text { week }\end{array}$ & \\
\hline Nut-intake, servings per day & $0-0.033$ & $0.034-0.10$ & $0.11-0.20$ & $0.21-0.60$ & $>0.60$ & \\
\hline \multicolumn{7}{|l|}{ All } \\
\hline Event & 999 & 1481 & 1615 & 1998 & 717 & \\
\hline Person-years & 171866 & 216234 & 237987 & 272132 & 100500 & \\
\hline Age-adjusted $^{a}$ & 1 & $1.08(1.00,1.18)$ & $1.11(1.02,1.20)$ & $1.11(1.03,1.20)$ & $1.04(0.93,1.16)$ & 0.54 \\
\hline MV1-adjusted ${ }^{b}$ & 1 & $1.05(0.97,1.14)$ & $1.07(0.99,1.16)$ & $1.07(0.98,1.15)$ & $1.00(0.90,1.11)$ & 0.85 \\
\hline MV2-adjusted ${ }^{c}$ & 1 & $1.04(0.96,1.13)$ & $1.06(0.98,1.15)$ & $1.05(0.97,1.14)$ & $0.98(0.89,1.09)$ & 0.61 \\
\hline \multicolumn{7}{|l|}{ Advanced $^{d}$} \\
\hline Event & 172 & 247 & 265 & 312 & 136 & \\
\hline Person-years & 172673 & 217410 & 239312 & 273755 & 101050 & \\
\hline Age-adjusted $^{a}$ & 1 & $1.16(0.95,1.41)$ & $1.19(0.98,1.45)$ & $1.18(0.97,1.43)$ & $1.23(0.97,1.56)$ & 0.20 \\
\hline MV1-adjusted ${ }^{b}$ & 1 & $1.15(0.94,1.40)$ & $1.18(0.97,1.44)$ & $1.17(0.96,1.42)$ & $1.22(0.96,1.55)$ & 0.23 \\
\hline MV2-adjusted ${ }^{c}$ & 1 & $1.13(0.93,1.38)$ & $1.15(0.94,1.40)$ & $1.13(0.93,1.37)$ & $1.18(0.93,1.50)$ & 0.40 \\
\hline \multicolumn{7}{|l|}{ Lethal $^{\mathrm{e}}$} \\
\hline Event & 149 & 190 & 193 & 233 & 107 & \\
\hline Person-years & 17694 & 217459 & 239383 & 273826 & 101074 & \\
\hline Age-adjusted $^{\mathrm{a}}$ & 1 & $1.05(0.84,1.30)$ & $1.02(0.82,1.26)$ & $1.02(0.83,1.27)$ & $1.11(0.85,1.43)$ & 0.58 \\
\hline MV1-adjusted ${ }^{b}$ & 1 & $1.05(0.84,1.31)$ & $1.02(0.82,1.27)$ & $1.02(0.83,1.27)$ & $1.11(0.85,1.44)$ & 0.58 \\
\hline MV2-adjusted ${ }^{c}$ & 1 & $1.04(0.83,1.29)$ & $1.00(0.80,1.24)$ & $0.99(0.80,1.23)$ & $1.07(0.82,1.40)$ & 0.78 \\
\hline \multicolumn{7}{|l|}{ Fatal } \\
\hline Event & 124 & 149 & 159 & 194 & 84 & \\
\hline Person-years & 172718 & 217500 & 239420 & 273860 & 101096 & \\
\hline Age-adjusted $^{a}$ & 1 & $1.00(0.79,1.28)$ & $1.02(0.80,1.30)$ & $1.03(0.82,1.31)$ & $1.03(0.77,1.38)$ & 0.76 \\
\hline MV1-adjusted ${ }^{b}$ & 1 & $1.01(0.79,1.29)$ & $1.03(0.81,1.31)$ & $1.05(0.83,1.33)$ & $1.05(0.78,1.40)$ & 0.71 \\
\hline MV2-adjusted ${ }^{c}$ & 1 & $1.00(0.78,1.27)$ & $1.01(0.79,1.28)$ & $1.00(0.79,1.27)$ & $1.01(0.75,1.36)$ & 0.94 \\
\hline \multicolumn{7}{|l|}{ Gleason score 2-6 } \\
\hline Event & 465 & 729 & 731 & 937 & 311 & \\
\hline Person-years & 172395 & 216965 & 238870 & 273166 & 100885 & \\
\hline Age-adjusted $^{\mathrm{a}}$ & 1 & $1.10(0.98,1.24)$ & $1.05(0.93,1.18)$ & $1.11(0.99,1.25)$ & $0.99(0.86,1.16)$ & 0.93 \\
\hline MV1-adjusted ${ }^{b}$ & 1 & $1.04(0.93,1.18)$ & $0.99(0.88,1.12)$ & $1.04(0.93,1.17)$ & $0.93(0.80,1.08)$ & 0.50 \\
\hline MV2-adjusted ${ }^{c}$ & 1 & $1.03(0.92,1.16)$ & $0.98(0.87,1.10)$ & $1.02(0.91,1.15)$ & $0.92(0.79,1.07)$ & 0.43 \\
\hline \multicolumn{7}{|l|}{ Gleason score $\geqslant 7$} \\
\hline Event & 264 & 434 & 526 & 661 & 233 & \\
\hline Person-years & 172575 & 217252 & 239075 & 273405 & 100979 & \\
\hline Age-adjusted $^{a}$ & 1 & $1.15(0.98,1.34)$ & $1.28(1.10,1.49)$ & $1.25(1.07,1.45)$ & $1.14(0.95,1.37)$ & 0.33 \\
\hline MV1-adjusted ${ }^{b}$ & 1 & $1.11(0.95,1.30)$ & $1.25(1.07,1.45)$ & $1.19(1.03,1.39)$ & $1.09(0.91,1.32)$ & 0.60 \\
\hline MV2-adjusted ${ }^{c}$ & 1 & $1.10(0.94,1.29)$ & $1.22(1.05,1.42)$ & $1.16(1.00,1.35)$ & $1.07(0.88,1.28)$ & 0.86 \\
\hline \multicolumn{7}{|c|}{ 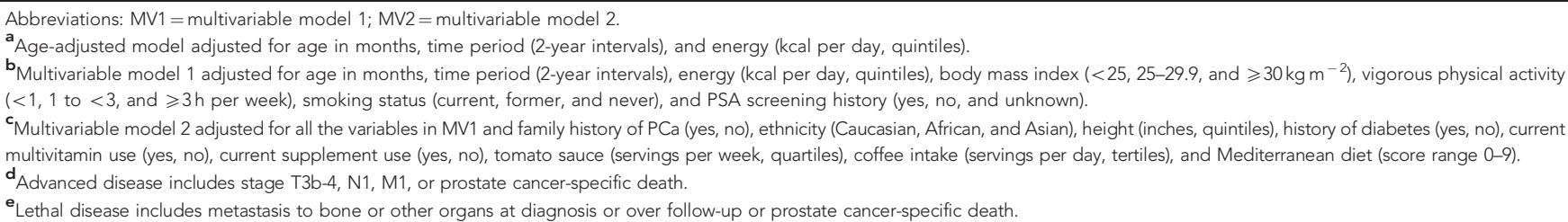 } \\
\hline
\end{tabular}


average from the date of diagnosis to end of follow-up. The FFQ immediately preceding diagnosis was used to classify the participants' diet from the diagnosis date until the next available FFQ, because it would better capture diet at the time of diagnosis without the diagnosis having affected diet. Similar secondary analyses to those above were performed. In addition, we included pre-diagnostic nut consumption from the 1986 FFQ in the multivariable models to mitigate the influence of pre-diagnostic diet.

\section{RESULTS}

Nut consumption and PCa incidence. During 26 years of followup, 6810 men were diagnosed with PCa. At baseline, men with higher nut consumption exercised more, took more vitamin supplements, had higher Mediterranean diet scores and drank more alcohol (Supplementary Table 1).

Nut consumption was not associated with being diagnosed with PCa (Table 1). Similarly, no significant associations were observed between peanut or other nut consumption and PCa incidence (data not shown). The null effect association remained unchanged when baseline nut intake was used as the main exposure, or after a 2-year lag period was added between nut-intake assessment and each follow-up period (data not shown). No significant interactions by age, BMI, or ethnicity were identified (all $P$ interactions $>0.05$ ).

Nut consumption and mortality in PCa patients. Among the 4346 men diagnosed with non-metastatic PCa, 359 cases of lethal PCa, 264 cases of fatal PCa, and 1285 total deaths were identified. The mean duration of follow-up was 7.8 years for lethal $\mathrm{PCa}$ and 10.3 years for fatal PCa. Compared with non-consumers, patients with higher nut consumption were more likely to take vitamin supplements, less likely to have high blood pressure, consumed more alcohol, olive oil, and tomatoes, and had a higher Mediterranean diet score (Supplementary Table 2).

There were no statistically significant associations between nut consumption after diagnosis and development of lethal or fatal PCa (Table 2). But patients who consumed nuts five or more times per week had a $34 \%$ lower rate of overall mortality compared with those who consumed less than once per month (HR: 0.66, 95\% CI: $0.52-0.83, P$ for trend=0.0005); (Table 2). We also observed a statistically significant difference in overall survival across nutintake categories $(P<0.0004$, Supplementary Figure 1).

Further adjustment for pre-diagnostic baseline nut consumption or adding a 2-year lag period did not alter these findings (data not shown). No significant interactions by age, BMI, or ethnicity were identified (all $P$ interactions $>0.05$ ). Although we observed no associations of peanuts or other nuts separately with lethal or fatal $\mathrm{PCa}$, the HRs for total mortality were 0.70 (95\% CI: $0.52-0.95$; $P$ for trend $=0.003)$ for other nuts and 0.79 (95\% CI: $0.59-1.06$; $P$ for trend $=0.01)$ for peanuts, comparing five or more servings per week with less than once per month.

\section{DISCUSSION}

To our knowledge, this is the largest cohort study to prospectively assess the association of nut consumption with being diagnosed with $\mathrm{PCa}$, including subtypes of aggressive $\mathrm{PCa}$. Our null effect results with PCa incidence are consistent with those of the Adventists Health Study (180 PCa cases and 6-year follow-up) (Mills et al, 1989), although they did not examine different subtypes of PCa. In contrast, two case-control studies reported inverse associations (Jain et al, 1999; Raimondi et al, 2010). However, case-control studies are prone

Table 2. Hazard ratios and $95 \%$ confidence intervals for prostate-specific and all-cause mortality among men diagnosed with non-metastatic prostate cancer, according to the total nut consumption

\begin{tabular}{|c|c|c|c|c|c|c|}
\hline & \multicolumn{5}{|c|}{ Frequency of total nut consumption ( $28 \mathrm{~g}$ serving) } & \multirow[b]{2}{*}{$P$ for trend } \\
\hline & $\begin{array}{l}\text { Less than once } \\
\text { per month }\end{array}$ & $\begin{array}{l}\text { Less than once } \\
\text { per week }\end{array}$ & Once per week & $\begin{array}{l}\text { 2-4 Times per } \\
\text { week }\end{array}$ & $\geqslant 5$ Times per week & \\
\hline $\begin{array}{l}\text { Nut-intake, servings } \\
\text { per day }\end{array}$ & $0-0.033$ & $0.034-0.10$ & $0.11-0.20$ & $0.21-0.60$ & $>0.60$ & \\
\hline \multicolumn{7}{|c|}{ Lethal prostate cancer } \\
\hline $\begin{array}{l}\text { Event } \\
\text { Person-years } \\
\text { Age-adjusted }^{\text {a }} \\
\text { MV1-adjusted }^{\mathbf{b}} \\
\text { MV2-adjusted }^{\mathbf{c}}\end{array}$ & $\begin{array}{c}52 \\
6504 \\
1 \\
1 \\
1\end{array}$ & $\begin{array}{c}66 \\
8633 \\
0.88(0.61,1.27) \\
0.87(0.60,1.26) \\
0.92(0.63,1.33)\end{array}$ & $\begin{array}{c}73 \\
9251 \\
0.91(0.63,1.30) \\
0.95(0.66,1.37) \\
0.99(0.68,1.42)\end{array}$ & $\begin{array}{c}122 \\
13529 \\
1.03(0.74,1.45) \\
1.06(0.75,1.49) \\
1.13(0.80,1.59)\end{array}$ & $\begin{array}{c}46 \\
6706 \\
0.79(0.52,1.20) \\
0.81(0.53,1.24) \\
0.88(0.57,1.35)\end{array}$ & $\begin{array}{l}0.72 \\
0.83 \\
0.89\end{array}$ \\
\hline \multicolumn{7}{|c|}{ Fatal prostate cancer } \\
\hline $\begin{array}{l}\text { Event } \\
\text { Person-years } \\
\text { Age-adjusted }^{\mathbf{a}} \\
\text { MV1-adjusted }^{\mathbf{b}} \\
\text { MV2-adjusted }^{\mathbf{c}}\end{array}$ & $\begin{array}{c}36 \\
7726 \\
1 \\
1 \\
1 \\
\end{array}$ & $\begin{array}{c}49 \\
9588 \\
0.87(0.56,1.35) \\
0.92(0.59,1.43) \\
0.91(0.59,1.43)\end{array}$ & $\begin{array}{c}60 \\
10231 \\
0.96(0.63,1.47) \\
1.02(0.66,1.56) \\
0.98(0.64,1.51)\end{array}$ & $\begin{array}{c}93 \\
14960 \\
1.00(0.67,1.48) \\
1.10(0.74,1.65) \\
1.16(0.77,1.74) \\
\end{array}$ & $\begin{array}{c}26 \\
7489 \\
0.55(0.32,0.93) \\
0.59(0.35,1.00) \\
0.62(0.36,1.07)\end{array}$ & $\begin{array}{l}0.09 \\
0.17 \\
0.38\end{array}$ \\
\hline \multicolumn{7}{|l|}{ All-cause mortality } \\
\hline $\begin{array}{l}\text { Event } \\
\text { Person-years } \\
\text { Age-adjusted }^{\mathbf{a}} \\
\text { MV1-adjusted }^{\mathbf{b}} \\
\text { MV2-adjusted }^{\mathbf{d}}\end{array}$ & $\begin{array}{c}203 \\
7772 \\
1 \\
1 \\
1\end{array}$ & $\begin{array}{c}266 \\
9588 \\
0.82(0.68,0.99) \\
0.91(0.75,1.09) \\
0.92(0.76,1.11)\end{array}$ & $\begin{array}{c}289 \\
10231 \\
0.80(0.67,0.97) \\
0.90(0.75,1.08) \\
0.91(0.76,1.10)\end{array}$ & $\begin{array}{c}380 \\
14960 \\
0.67(0.56,0.79) \\
0.78(0.65,0.93) \\
0.85(0.71,1.01)\end{array}$ & $\begin{array}{c}147 \\
7489 \\
0.52(0.41,0.65) \\
0.58(0.47,0.73) \\
0.66(0.52,0.83)\end{array}$ & $\begin{array}{r}<0.0001 \\
<0.0001 \\
0.0005\end{array}$ \\
\hline \multicolumn{7}{|c|}{ 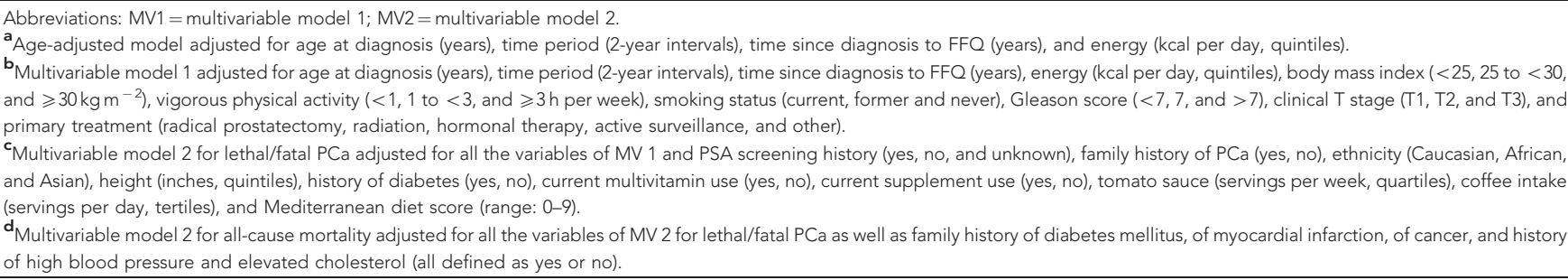 } \\
\hline
\end{tabular}


to recall bias and do not have long-term and repeated measures of dietary intake. In addition, Jain et al, (1999) combined nuts with beans and lentils, which could also explain the difference in results.

We observed a reasonably large, albeit non-significant, HR of 0.62 between post-diagnosis nut consumption and fatal outcome among PCa patients. This is consistent with a recent study that found an $18 \%$ lower rate of lethal $\mathrm{PCa}(\mathrm{HR}, 0.82 ; 95 \% \mathrm{CI}$, $0.67-1.01)$ per daily serving increase of nut intake after diagnosis (Richman et al, 2013). In addition, our finding of a significant $34 \%$ rate reduction in overall mortality is consistent with other prospective studies, Richman et al, (2013) included, which have found inverse associations between nuts and mortality, with HRs ranging from 0.61 to 0.87 (Bao et al, 2013; Guasch-Ferré and Bulló, 2013; Richman et al, 2013; Hshieh et al, 2015; Luu et al, 2015).

Our study suggests that nuts, although not associated with being diagnosed with PCa, may still improve the overall survival of PCa patients. Among PCa patients in the HPFS, cardiovascular disease was the leading cause of death, accounting for nearly one-third of the deaths (Richman et al, 2013; Kenfield et al, 2014). Large cohort studies have consistently shown that increased nut consumption was associated with reduced cardiovascular disease incidence and mortality $(\mathrm{Hu}, 2003$; Kelly and Sabaté, 2007; Kris-Etherton et al, 2008). Nuts are dense in nutrients and bioactive compounds that may confer cardio-protective, antiinflammatory, and antioxidant properties (Kris-Etherton et al, 2008; Bao et al, 2013). Furthermore, nuts are rich in monounsaturated and polyunsaturated fats, and replacement of carbohydrates and animal fat with either unsaturated fats has been shown to reduce all-cause mortality and lethal outcomes among men with non-metastatic PCa (Richman et al, 2013).

The strengths of this study include its prospective design, large sample size, long follow-up time with excellent retention, and repeated measurement of diet and lifestyle factors. We were also able to reduce random measurement error by averaging nut intake cumulatively from multiple time points. However, there may still be residual confounding, although we adjusted extensively for risk factors for PCa development and survivorship.

In conclusion, nut consumption was not associated with $\mathrm{PCa}$ incidence or $\mathrm{PCa}$-specific mortality in this large and prospective cohort of men. However, frequent nut consumption was associated with significantly lower overall mortality rate among men diagnosed with non-metastatic PCa.

\section{ACKNOWLEDGEMENTS}

We would like to thank the participants and staff of the HPFS for their valuable contributions as well as the following state cancer registries for their help: AL, AZ, AR, CA, CO, CT, DE, FL, GA, ID, IL, IN, IA, KY, LA, ME, MD, MA, MI, NE, NH, NJ, NY, NC, ND, OH, OK, OR, PA, RI, SC, TN, TX, VA, WA, and WY. This study was supported by the grants UM1 CA167552, U54CA155626, and P30DK046200 from the National Institutes of Health and by a grant from the International Tree Nut Council Nutrition Research \& Education Foundation. This work was also conducted with the support of a KL2/Catalyst Medical Research Investigator Training award (an appointed KL2 award) from Harvard Catalyst: The Harvard Clinical and Translational Science Center (National Center for Research Resources and the National Center for Advancing Translational Sciences, and National Institutes of Health Award KL2 TR001100). The content is solely the responsibility of the authors and does not necessarily represent the official views of Harvard Catalyst, Harvard University and its affiliated academic healthcare centres, or the National Institutes of Health.

\section{CONFLICT OF INTEREST}

Dr Bao received a research grant from the International Tree Nut Council Nutrition Research \& Education Foundation. The other authors declare no conflict of interest.

\section{REFERENCES}

Afshin A, Micha R, Khatibzadeh S, Mozaffarian D (2014) Consumption of nuts and legumes and risk of incident ischemic heart disease, stroke, and diabetes: a systematic review and meta-analysis. Am J Clin Nutr 100(1): 278-288.

American Cancer Society (2015) Cancer Facts and Figures 2015. American Cancer Society: Atlanta, GA, USA.

Bao Y, Han J, Hu FB, Giovannucci EL, Stampfer MJ, Willett WC, Fuchs CS (2013) Association of nut consumption with total and cause-specific mortality. N Engl J Med 369(21): 2001-2011.

González CA, Salas-Salvadó J (2007) The potential of nuts in the prevention of cancer. Br J Nutr 96(S2): S87-S88.

Guasch-Ferré M, Bulló M (2013) Frequency of nut consumption and mortality risk in the PREDIMED nutrition intervention trial. BMC Med 11(1): 164-175.

Hebert JR, Hurley TG, Olendzki BC, Teas J, Ma Y, Hampl JS (1998) Nutritional and socioeconomic factors in relation to prostate cancer mortality: a cross-national study. J Natl Cancer Inst 90(21): 1637-1647.

Hshieh TT, Petrone AB, Gaziano JM, Djousse L (2015) Nut consumption and risk of mortality in the Physicians' Health Study. Am J Clin Nutr 101(2): 407-412.

Hu FB (2003) Plant-based foods and prevention of cardiovascular disease: an overview. Am J Clin Nutr 78(3): 544S-551S.

Jain MG, Hislop GT, Howe GR, Ghadirian P (1999) Plant foods, antioxidants, and prostate cancer risk: findings from case-control studies in Canada. Nutr Cancer 34(2): 173-184.

Kris-Etherton PM, Hu FB, Ros E, Sabaté J (2007) Nuts and coronary heart disease: an epidemiological perspective. Br J Nutr 96(S2): S61-S76.

Kenfield SA, DuPre N, Richman EL, Stampfer MJ, Chan JM, Giovannucci EL (2014) Mediterranean diet and prostate cancer risk and mortality in the Health Professionals Follow-up Study. Eur Urol 65(5): 887-894.

Kelly Jr JH, Sabaté J (2007) Nuts and coronary heart disease: an epidemiological perspective. Br J Nutr 96(S2): S61-S76.

Luu HN, Blot WJ, Xiang YB, Cai H, Hargreaves MK, Li H, Yang G, Signorello L, Gao YT, Zheng W, Shu XO (2015) Prospective evaluation of the association of nut/peanut consumption with total and cause-specific mortality. JAMA Intern Med 175(5): 755-766.

Mills PK, Beeson WL, Phillips RL, Fraser GE (1989) Cohort study of diet, lifestyle, and prostate cancer in Adventist men. Cancer 64(3): 598-604.

Raimondi S, Mabrouk JB, Shatenstein B, Maisonneuve P, Ghadirian P (2010) Diet and prostate cancer risk with specific focus on dairy products and dietary calcium: a case-control study. Prostate 70(10): 1054-1065.

Richman EL, Kenfield SA, Chavarro JE, Stampfer MJ, Giovannucci EL, Willett WC, Chan JM (2013) Fat intake after diagnosis and risk of lethal prostate cancer and all-cause mortality. JAMA Intern Med 173(14): 1318-1326.

Ros E (2010) Health benefits of nut consumption. Nutrients 2(7): 652-682.

Ros E, Tapsell LC, Sabaté J (2010) Nuts and berries for heart health. Curr Atheroscler Rep 12(6): 397-406.

Salvini S, Hunter DJ, Sampson L, Stampfer MJ, Colditz GA, Rosner B, Willett WC (1989) Food-based validation of a dietary questionnaire: the effects of week-to-week variation in food consumption. Int J Epidemiol 18(4): 858-867.

Siegel RL, Miller KD, Jemal A (2015) Cancer statistics 2015. CA Cancer J Clin 65(1): 5-29.

This work is published under the standard license to publish agreement. After 12 months the work will become freely available and the license terms will switch to a Creative Commons AttributionNonCommercial-Share Alike 4.0 Unported License.

Supplementary Information accompanies this paper on British Journal of Cancer website (http://www.nature.com/bjc) 